\title{
PENGARUH DOSIS TABLET MIKORIZA TERHADAP BEBERAPA JENIS STEK MERANTI DI HPH PT ITCIKU, BALIKPAPAN KALIMANTAN TIMUR
}

\author{
The Effect of Mycorrhizal Tablet Dosage on the Growth of Several Cuttings of Meranti \\ Species at PT. ITCIKU Concession Holder, Balikpapan, East Kalimantan \\ R. Mulyana Omon \\ Balai Penelitian Teknologi Perbenihan Samboja \\ Jl. Soekarno-Hatta Km. 38, Semboja PO. Box 578 Balikpapan 76112 \\ Telp. (0542) 7217663 Fax. (0542) 7217665
}

Naskah masuk : 20 Pebruari 2009; Naskah diterima : 31 Juli 2009

\begin{abstract}
A study on the effect of mycorrhizal tablet dosage on the growth of several meranti species cuttings was conducted at PT. ITCIKU concession holder, Balikpapan East Kalimantan. The purpose of this research was to determine the optimum dosage of mycorrhizal tablet inoculums on the growth of five meranti species from cuttings. Treatments consisted of five meranti species and three inoculums dosages of mycorrhizal tablets (without mycorrhizal as control, one tablet and two tablets) per seedling. Mycorrhizal tablet was made from top-soil, Scleroderma columnare fungi and anorganic fertilizer $\left(\mathrm{P}_{2} \mathrm{O}_{5}\right)$ with weight ratio (50:1:1). Factorial completely randomized Block design with three replications was used for this study. After inoculation, seedlings were grown for four months in nursery before planting in the field. Each treatment consisted of 15 plants were planted with $6 \times 3 \mathrm{~m}$ spacing. The total numbers of plants observed were 675 plants. The results showed that different dosages and their interactions had no significant effect on the survival rate, but species treatment gave significant difference on the survival percentage. The survival percentage of Shorea johorensis was higher than other species as much as $83.70 \%$. While for height growth S. leprosula had the most growth compared with other species as much as $57.87 \mathrm{~cm}$. Therefore $S$. leprosula from cuttings is recommended for planting in forest rehabilitation program.
\end{abstract}

Key words : meranti, cuttings, mycorrhizal tablet

\begin{abstract}
ABSTRAK
Penelitian pengaruh dosis tablet fungi mikoriza terhadap pertumbuhan stek beberapa jenis meranti merah telah dilakukan di areal Hak Pengusahaan Hutan PT. ITCIKU, Balikpapan, Kalimantan Timur. Penelitian ini bertujuan untuk mengetahui dosis tablet mikoriza yang efektif terhadap pertumbuhan lima jenis meranti merah yang berasal dari stek. Perlakuan terdiri dari lima jenis meranti merah dan tiga dosis tablet fungi mikoriza (kontol negatif tanpa diberi tablet mikoriza, satu tablet dan dua tablet mikoriza). Tablet fungi mikoriza dibuat dari campuran top-soil, fungi Scleroderma columnare dan pupuk anorganik $\left(\mathrm{P}_{2} \mathrm{O}_{5}\right)$ dengan perbandingan berat (50:1:1). Rancangan percobaan yang digunakan adalah faktorial dalam pola acak lengkap yang diulang sebanyak tiga kali. Sebelum bibit ditanam, dilakukan inokulasi dengan tablet fungi mikoriza dan setelah empat bulan di persemaian, kemudian ditanam di lapangan. Setiap perlakuan menggunakan 15 tanaman dengan jarak tanam $6 \times 3 \mathrm{~m}$. Jumlah tanaman yang diamati sebanyak 675 tanaman. Hasil penelitian menunjukkan bahwa perlakuan dosis fungi tablet mikoriza dan interaksinya tidak berpengaruh nyata terhadap persen hidup dan pertumbuhan tanaman, tetapi perlakuan jenis memberikan pengaruh yang nyata terhadap persen hidup. Persen hidup Shorea. johorensis lebih tinggi dibandingkan dengan jenis lainnya yaitu sebesar $83,70 \%$. Sedangkan untuk jenis (S. leprosula) memberikan pengaruh yang nyata terhadap pertumbuhan tinggi dibanding dengan jenis meranti lainnya, yaitu sebesar $83,70 \mathrm{~cm}$. Dengan demikian jenis $S$. leprosula dari stek dapat direkomendasikan untuk ditanam dalam program rehabilitasi lahan hutan.
\end{abstract}

Kata kunci : meranti, stek, tablet mikoriza 


\section{PENDAHULUAN}

Lahan kritis di Indonesia pada saat ini mencapai 77,8 juta ha, termasuk lahan kritis di hutan produksi akibat penebangan yang telah mencapai 37 juta ha (Gintings dan Dharmawan, 2007). Untuk mengembalikan fungsi lahan yang telah kritis tersebut, perlu segera dilakukan rehabilitasi. Untuk menunjang kegiatan tersebut tentunya diperlukan bibit dalam jumlah yang besar dengan kualitas yang baik.

Seperti diketahui, kegagalan rehabilitasi lahan hutan antara lain diakibatkan oleh kualitas bibit yang belum memenuhi mutu standar. Selama ini kondisi fisik lahan juga berperan dalam kegagalan rehabilitasi lahan hutan. Di Kalimantan Timur, lahan yang akan direhabilitasi pada umumnya memiliki $\mathrm{pH}$ yang rendah, lapisan top-soil tipis dan miskin unsur hara terutama fosfor (P). Hal tersebut menyebabkan banyak tanaman yang mengalami stress (transplant shock) di lapangan dan mengakibatkan kematian bibit setelah ditanam (Omon,2002).

Untuk mengatasi rendahnya kualitas bibit terutama dari jenis dipterokarpa tersebut di persemaian, diupayakan penggunaan mikoriza sebagai pupuk hayati. Fungi mikoriza dengan akar tanaman inangnya dalam siklus hidupnya akan membentuk proses simbiosis yang bersifat obligat (Smits, 1994). Keuntungan dari adanya simbiosis tersebut, yaitu dapat meningkatkan penyerapan air dan unsur hara terutama fosfor ke tanaman inang, fungi mikoriza mendapat karbohidrat hasil fotosintesis dari tanaman. Keuntungan lain dengan adanya fungi mikoriza yaitu fungi ini dapat meningkatkan ketahanan akar tanaman terhadap serangan patogen dan kekeringan (Mark dan Foster, 1973; Malajczuk et al., 1994) dan dapat memproduksi hormon tumbuh IAA (Gay dan Debaud, 1987), serta memperbaiki struktur tanah (De la Cruz, 1982). Oleh karena itu fungi mikoriza mempunyai peranan penting dalam meningkatkan kualitas pertumbuhan, khususnya pada tanaman jenis dipterokarpa yang sangat bergantung pada mikoriza.

Penularan fungi mikoriza pada akar tanaman (inang) dapat terbentuk setelah terjadi proses infeksi fungi mikoriza ke dalam akar tanaman baik yang diawali dengan berkecambahnya spora maupun infeksi oleh bagian vegetatif dari jamur mikoriza (Supriyanto et al., 2003). Penularan tersebut dapat terjadi baik secara alami maupun dengan bantuan manusia (Supriyanto et al., 2003). Inokulasi dengan bantuan manusia dapat dilakukan dengan tablet atau kapsul, alginate mikoriza, spora dan miselium (Supriyanto, 1996).

Penyediaan bibit dari jenis Dipterocarpaceae tidak mudah dilakukan dengan cara generatif, karena masa berbunga dan berbuah massal (panen raya) tidak terjadi sepanjang tahun dan benih tidak dapat disimpan lama. Namun jenis ini dapat dibiakkan secara vegetatif melalui stek pucuk dengan mudah terutama untuk jenis Shorea johorensis dan S. leprosula baik pada media padat maupun cair (Priadjati dan Tolkamp, 2002).

Tujuan penelitian ini adalah untuk mengetahui dosis tablet mikoriza yang efektif untuk 4 jenis meranti merah dan satu meranti putih dari bibit yang berasal dari stek. Diharapkan, hasil penelitian ini dapat memberikan informasi terhadap penanaman jenis meranti dalam rangka menunjang program rehabilitasi hutan alam dengan bibit berasal dari stek.

\section{BAHAN DAN METODE}

\section{A. Lokasi dan Waktu}

Pembuatan petak coba aplikasi tablet ektomikoriza pada lima jenis, yaitu Shorea pauciflora, $S$. johorensis, S. leprosula, S. smithiana dan S. javanica telah dilakukan pada areal hutan belukar yang pada umumnya didominasi oleh jenis Piper sp. (sirih-sirihan) di areal Izin Usaha Pemanfaatan Hasil Hutan Kayu (IUPHHK) PT. ITCIKU, Kenangan Balikpapan, Kalimantan Timur. Lokasi tersebut secara administratif termasuk desa Kenangan, Kecamatan Penajam, Kabupaten Penajam Paser Utara, Provinsi Kalimantan Timur.

Jenis tanah di lokasi penelitian termasuk Podsolik Merah Kuning yang pada umumnya memiliki pH 3- 4 (rendah) dan lapisan top soil kurang dari $10 \mathrm{~cm}$ dan miskin unsur hara terutama fosfor (P). Berdasarkan klasifikasi iklim Schmidt dan Ferguson (1951) daerah tersebut termasuk tipe iklim A dengan rata-rata curah hujan tahunan berkisar antara 1.682 - $2.314 \mathrm{~mm}$ dan hari hujan 72 - 154 hari. Ketinggian tempatnya antara $40-150 \mathrm{~m}$ dpl. 
Penelitian dilakukan pada pertengahan tahun 2005 dan dimulai dengan proses perakaran bibit stek jenis $S$. pauciflora, S. javanica, S. johorensis, S. leprosula dan S. smithiana. Setelah empat bulan stek diinokulasi dengan tablet mikoriza di persemaian, kemudian ditanam pada bulan Februari 2006 dan diamati satu tahun setelah penanaman, yaitu bulan Februari 2007.

\section{B. Bahan}

Bahan yang digunakan adalah stek dari jenis $S$. pauciflora, S. javanica, S. johorensis, S. leprosula dan S. smithiana. Bahan stek diambil dari kebun pangkas yang telah berumur dua tahun, kemudian dilakukan proses perakaran pada media padat (pasir) yang sebelumnya diberi hormon perangsang Rootone F berbentuk pasta dengan cara dioles di persemaian PT. ITCIKU. Setelah bibit-bibit tersebut berakar, kemudian disapih dalam kantong plastik berisi tanah yang telah disterilkan dengan cara digoreng. Setelah dua minggu bibit-bibit tersebut disapih, kemudian dilakukan inokulasi dengan spora fungi Scleroderma columnare yang diformulasikan dalam bentuk tablet.

Tablet mikoriza dibuat dari tanah yang telah disterilkan, kemudian diayak halus dan dicampur dengan spora $S$. columnare, dan pupuk anorganik $\left(\mathrm{P}_{2} \mathrm{O}_{5}\right)$ dengan perbandingan berat 50:1:1. Selanjutnya diaduk merata dan diberi air secukupnya agar mudah dicetak. Tablet kemudian dikeringanginkan dan dimasukkan ke dalam kantong plastik dan disimpan pada suhu pada suhu $20^{\circ} \mathrm{C}$. Berat tablet antara $0,67 \mathrm{~g}$ 0,72 g dengan jumlah spora sebanyak $10.000-16.000$ spora per tablet. Pembuatan tablet mikoriza tersebut dilakukan di Laboratorium Mikoriza Loka Litbang Satwa Primata yang sejak Juli 2007 menjadi Balai Penelitian Teknologi Perbenihan, Samboja, Kalimantan Timur. Berdasarkan hasil pengamatan tablet ini dapat disimpan maksimal selama 3 bulan pada suhu $4^{\circ} \mathrm{C}$ atau $20^{\circ} \mathrm{C}(\mathrm{Omon}, 2006)$. Penyulaman dilakukan setelah bibit berumur tiga bulan tanam dan pemeliharaan dilakukan setiap tiga bulan sekali atau empat kali dalam setahun.

\section{Rancangan Percobaan}

Petak coba dibuat berukuran $75 \times 45 \mathrm{~m}$ dengan jarak tanam $6 \times 3 \mathrm{~m}$. Rancangan percobaan yang dilakukan adalah faktorial $5 \times 3$, dengan pola rancangan acak lengkap kelompok yaitu:

Faktor A adalah jenis terdiri dari :

$$
\begin{aligned}
& \text { A1 }=\text { Shorea pauciflora } \\
& \text { A2 }=\text { Shorea javanica } \\
& \text { A3 }=\text { Shorea johorensis } \\
& \text { A4 }=\text { Shorea leprosula } \\
& \text { A5 }=\text { Shorea smithiana }
\end{aligned}
$$

Faktor B adalah bibit yang dinokulasi dengan tablet mikoriza, yaitu :

$$
\begin{aligned}
& \mathrm{B} 0=\text { tidak dinokulasi } \\
& \mathrm{B} 1=\text { diinokulasi dengan satu tablet } \\
& \mathrm{B} 2=\text { diinokulasi dengan dua tablet }
\end{aligned}
$$

Setiap kombinasi perlakuan ditanam masing-masing sebanyak 15 bibit dengan ulangan sebanyak tiga kali. Jumlah bibit yang diamati sebanyak 675 bibit.

Parameter yang diukur adalah persen hidup dan pertambahan tinggi (riap) di lapangan. Analisis data yang digunakan adalah analisis sidik ragam (ANOVA). Apabila ada perbedaan nyata antar perlakuan dilanjutkan dengan uji lanjutan Tukey (Haeruman, 1975).

\section{HASIL DAN PEMBAHASAN}

\section{A. Persentase kolonisasi akar bermikoriza}

Bibit stek yang diinokulasi dengan tablet mikoriza terhadap lima jenis meranti dan yang tidak diinokulasi menunjukkan persen kolonisasi antara 49 - 63\%, tetapi secara analisis keragaman tidak menunjukkan perbedaan yang nyata $(\mathrm{P}>0.05)$.

Bibit yang tidak diinokulasi dengan tablet mikoriza, persentase kolonisasi akar bermikorizanya 
berkisar antara 49 - 52\% (Tabel 1). Kolonisasi akar bermikoriza tersebut diduga berasal dari fungi yang berasal dari air dan udara, tetapi keberadaan fungi tersebut tidak mematikan bibit. Omon (2002 dan 2006) menyatakan bahwa persentase kolonisasi akar yang terjadi pada perlakuan tanpa inokulasi bibit stek $S$. leprosula dan S. johorensis masing-masing 21\% dan 58\% di rumah kaca. Oldeman (2001) mengemukakan fungi tersebut pada umumnya termasuk dalam kelompok early stage, yaitu Thelophora sp., Inocybe sp. dan Hebloma sp. yang biasa terdapat di rumah kaca dan di persemaian, yang termasuk juga ke dalam kelompok fungi mikoriza pionir.

Tabel (Table) 1. Rata-rata persentase kolonisasi akar bermikoriza pada stek S. pauciflora, S. javanica, S. johorensis, S. leprosula dan S. smithiana setelah empat bulan diinokulasi di persemaian (Average of percentage of mycorrhizal root colonization of S. pauciflora, S. javanica, S. johorensis, S. leprosula and S. smithiana cuttings, four months after inoculation in nursery)

\begin{tabular}{|l|c|c|c|}
\hline Jenis (Species) & \multicolumn{3}{|c|}{ Persen kolonisasi (Colonization percentage) (\%) } \\
\hline & $\begin{array}{c}\text { Kontrol } \\
\text { (0 tablet) }\end{array}$ & $\begin{array}{c}\text { Satu tablet } \\
\text { (one tablet) }\end{array}$ & $\begin{array}{c}\text { Dua tablet } \\
\text { (two tablets) }\end{array}$ \\
\hline S. pauciflora & $52 \pm 4,3$ & $61 \pm 3,7$ & $63 \pm 3,2$ \\
\hline S. javanica & $49 \pm 3,0$ & $52 \pm 3,0$ & $61 \pm 2,5$ \\
\hline S. johorensis & $50 \pm 4,3$ & $52 \pm 2,8$ & $60 \pm 4,5$ \\
\hline S. leprosula & $49 \pm 2,0$ & $50 \pm 2,8$ & $63 \pm 3,0$ \\
\hline S. smithiana & $51 \pm 4,3$ & $52 \pm 2,8$ & $61 \pm 4,5$ \\
\hline
\end{tabular}

\section{B. Persentase Hidup}

Hasil analisis keragaman menunjukkan bahwa blok, dosis tablet mikoriza dan interaksi antara perlakuan jenis dan tablet mikoriza tidak menunjukkan perbedaan yang nyata terhadap persen hidup stek setelah satu tahun ditanam di lapangan. Sementara perlakuan jenis telah memberikan perbedaan yang sangat nyata terhadap persen hidup stek jenis meranti. Hasil uji beda nyata Tukey pada taraf $\mathrm{W}_{(0,05)}$ sebesar 16,23 menunjukkan bahwa persen hidup jenis $S$. johorensis lebih tinggi dibandingkan dengan jenis lainnya, yaitu sebesar $83,70 \%$, kemudian diikuti S. leprosula sebesar 78,52\%, S. javanica sebesar $77,03 \%$, S. smithiana sebesar $66,67 \%$ dan terakhir $S$. pauciflora sebesar $65,92 \%$ seperti terlihat pada Gambar 1 . Jika dilihat persen hidup jenis $S$. johorensis cukup baik yaitu di atas 80\%. Daryadi dan Harjono (1972) melaporkan dengan besar persentase hidup tersebut selama satu tahun ditanam dikategorikan cukup baik.

Walaupun persen hidup jenis $S$. johorensis yang tertinggi, tetapi berdasarkan hasil uji beda nyata Tukey persen hidup tersebut tidak berbeda nyata dibandingkan S. leprosula dan S. javanica (Gambar 1). Perbedaan antar jenis cenderung disebabkan oleh faktor genetik, lingkungan tempat tumbuh, dan kesesuaian atau asosiasi fungi terhadap jenis tersebut. Harley dan Smiths (1983) menyatakan bahwa setiap jenis mempunyai kesesuaian atau asosiasi dengan funginya seperti pada jenis Betula pedula dan Betula pubescens. Untuk pertumbuhan jenis S. leprosula dibutuhkan paling sedikit 30 hari hujan dan 4 bulan dalam musim kemarau (Ardikoesuma dan Noerkamal, 1955). Selain itu jenis ini dapat tumbuh di tempat yang tidak beroksigen $\left(\mathrm{O}_{2}\right)$ selama lebih kurang 75 hari (Ardikoesuma dan Noerkamal, 1955). Hal ini sesuai dengan kondisi pada waktu bibit ditanam, yaitu pada waktu penanaman bulan Febuari 2006 dimana telah turun hujan lebih kurang satu bulan dan bulan berikutnya terjadi musim kemarau berkepanjangan sampai lebih dari empat bulan. Untuk pertumbuhannya S. johorensis dan S. javanica membutuhkan kondisi yang sama dengan S. leprosula. Subiakto dkk. (2007) melaporkan bahwa kondisi lahan yang dibutuhkan untuk penanaman jenis $S$. leprosula dan $S$. johorensis adalah dengan curah hujan $>$ $2500 \mathrm{~mm}$ di lokasi dataran rendah. 


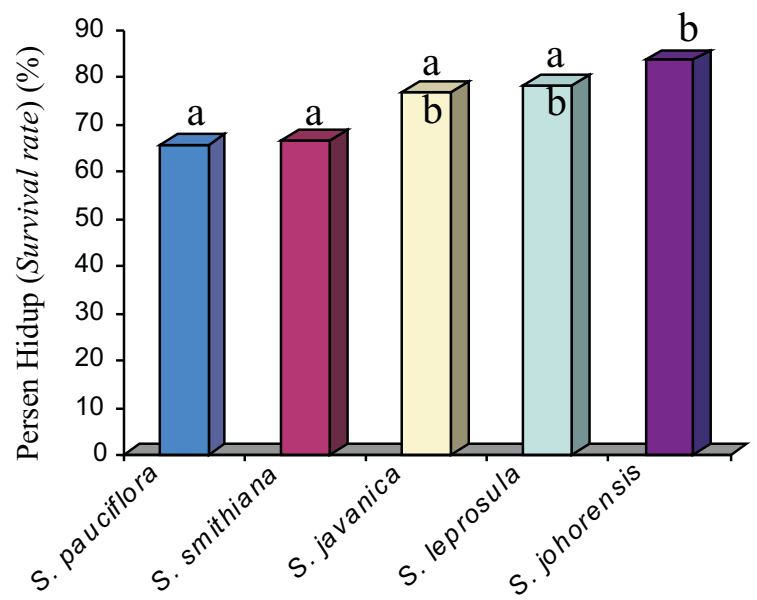

Gambar(Figure) 1. Hasil uji beda nyata Tukey perlakuan jenis terhadap persentase hidup setelah satu tahun ditanam di lapangan (Results of Tukey significant different test of species treatment to survival rate after one year in the field). Nilai rata-rata yang diikuti oleh huruf berbeda menunjukkan perbedaan nyata pada tingkat $5 \%$ berdasarkan uji beda nyata Tukey (Mean values followed by different letters are significant different at $5 \%$ level based on Tukey significant different test)

\section{Pertambahan Tinggi (Riap Tinggi)}

Seperti pada persen hidup, hasil analisis keragaman riap tinggi menunjukkan bahwa dosis tablet mikoriza dan interaksi antara perlakuan jenis tanaman dan tablet mikoriza tidak menunjukkan pengaruh yang nyata terhadap riap tinggi tanaman, tetapi perlakuan jenis dan blok menunjukkan perbedaan yang nyata terhadap riap tinggi.

Hasil uji beda nyata Tukey pada taraf W (0.05) sebesar 12,30 menunjukkan bahwa riap tinggi jenis S. leprosula lebih besar dibandingkan dengan jenis lainnya yaitu sebesar $57,87 \mathrm{~cm}$. Selanjutnya diikuti oleh riap tinggi lainnya yaitu masing-masing untuk $S$. javanica sebesar $41,09 \mathrm{~cm}, S$. johorensis sebesar $30,59 \mathrm{~cm}$, S. pauciflora sebesar $27,31 \mathrm{~cm}$ dan $S$. smithiana sebesar $23,21 \mathrm{~cm}$.

Untuk hasil uji beda nyata Tukey pada taraf W (0.05) sebesar 4,48 terhadap blok bahwa riap tinggi pada blok III menunjukkan perbedaan yang nyata dibandingkan pada Blok II dan I, yaitu masing-masing sebesar $42,14 \mathrm{~cm}, 34,62 \mathrm{~cm}$, dan $31,28 \mathrm{~cm}$. Untuk lebih jelas hasil uji beda nyata Tukey disajikan pada Gambar 2 dan 3. 


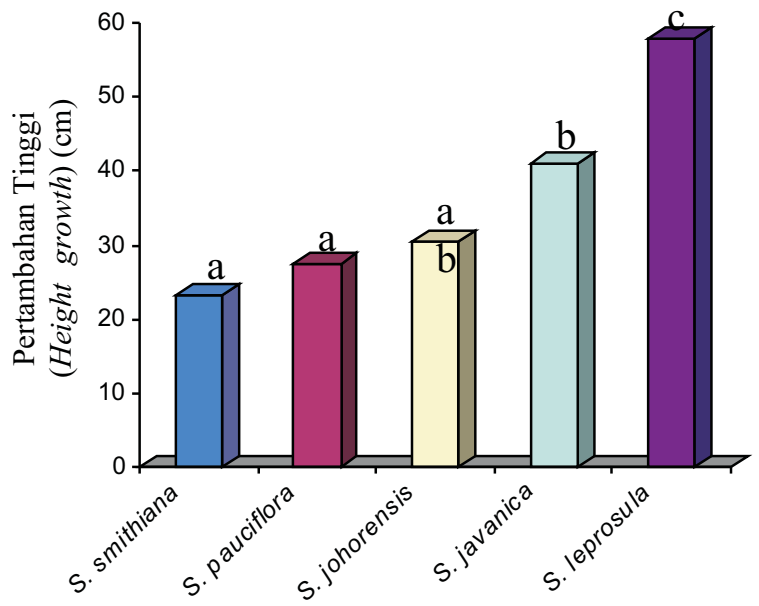

Gambar(Figure)2. Uji beda nyata Tukey perlakuan jenis terhadap pertambahan tinggi (riap tinggi) setelah satu tahun ditanam di lapangan (Results of Tukey significant different test of species to height growth after one year in the field). Nilai rata-rata yang diikuti oleh huruf berbeda menunjukkan perbedaan nyata pada tingkat $5 \%$ berdasarkan uji beda nyata Tukey (Mean values followed by different letters are significant different at $5 \%$ level based on Tukey significant different test)

Perlakuan jenis $S$. leprosula menunjukkan pertambahan tinggi yang tercepat dibandingkan jenis lainnya. Seperti dilaporkan oleh Soekotjo (2007) pada uji jenis dipterokarpa di PT Sari Bumi Kusuma, untuk $S$. leprosula menunjukkan rataan riap tinggi tercepat dibandingkan dengan jenis Shorea lainnya pada umur 4,5 tahun.

Blok III telah memberikan riap tinggi tercepat bagi kelima jenis stek meranti. Seperti diketahui kondisi di blok III masih terdapat vegetasi pionir lainnya seperti Nuclea sp., Macaranga gigantea, Schima walichii dan Anthocephalus cadamba selain Paper sp. Hal ini diduga kondisi lingkungan di Blok III sesuai dengan persyaratan kondisi lahan yang dibutuhkan untuk pertumbuhan kelima jenis ini. Yassir dan Mitikauji (2007) melaporkan bahwa pertumbuhan tanaman sangat dipengaruhi oleh interaksi tiga faktor, yaitu faktor keturunan (genetik), lingkungan dan teknik silvikultur.

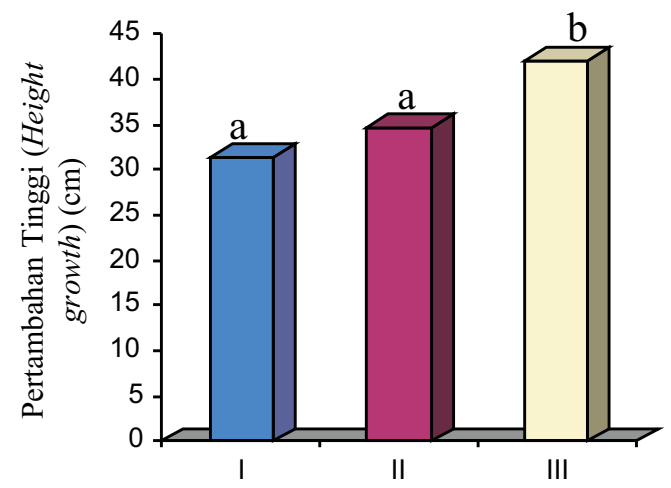

Gambar(Figure) 3. Uji beda nyata Tukey blok terhadap pertambahan tinggi setelah satu tahun ditanam di lapangan (Results of Tukey significant different test of block to height growth after one year in the field). Nilai rata-rata yang diikuti oleh huruf berbeda menunjukkan perbedaan nyata pada tingkat $5 \%$ berdasarkan uji beda nyata Tukey (Mean values followed by different letters are significant different at 5\% level based on Tukey significant different test) 
Tidak adanya pengaruh inokulasi tablet mikoriza terhadap persen hidup dan riap tinggi tanaman muda pada kelima jenis meranti diduga disebabkan karena inokulum hanya satu jenis fungi (single species), sehingga belum berperan optimal terhadap pertumbuhan kelima tanaman muda meranti merah di lapangan. Seperti dilaporkan oleh Supriyanto et al. (2003), jenis fungi S. columnare ini termasuk jenis pionir dan hanya berperan optimal pada tingkat semai di persemaian.

Hasil penelitian Supriyanto et al. (2003) menunjukkan bahwa penggunaan spora campuran dari beberapa jenis fungi ektomikoriza atau cocktail mikoriza dari jenis Amanita sp., Russulla sp. dan $S$. columare menghasilkan pertumbuhan stek S. leprosula yang lebih baik dibandingkan dengan spora dari satu jenis fungi. Amanita sp. dan Russulla sp. dikenal sebagai cendawan late stage yang akan berperan optimal pada kondisi vegetasi hutan yang telah mantap. Dengan demikian untuk penanaman jenis dipterokarpa sebaiknya menggunakan inokulasi dari inokulan campuran spora dari beberapa jenis cendawan mikoriza atau cocktail dibandingkan dengan satu jenis fungi. Asosiasi fungi yang terbentuk dari inokulan campuran diharapkan dapat memberi peran lebih efektif baik pada tingkat bibit maupun setelah penanaman di lapangan.

\section{KESIMPULAN DAN SARAN}

\section{A. Kesimpulan}

1. Inokulasi dengan tablet mikoriza terhadap lima jenis Shorea (Shorea smithiana, Shorea pauciflora, Shorea johorensis, Shorea javanica, dan Shorea leprosula) tidak menghasilkan persen hidup dan riap tinggi yang efektif.

2. Shorea johorensis, Shorea leprosula dan Shorea javanica memiliki persen hidup masing-masing sebesar $83,70 \%, 78,52 \%$ dan $77,03 \%$.

3. Riap tinggi Shorea leprosula lebih tinggi dibandingkan dengan jenis lainnya yaitu sebesar $57,87 \mathrm{~cm}$.

4. Belum efektifnya pemberian inokulum tablet mikoriza terhadap pertumbuhan kelima jenis Shorea, diduga tablet yang dikemas hanya terdiri satu jenis fungi mikoriza (single species).

\section{B. Saran}

Untuk aplikasi di lapangan sebaiknya menggunakan jenis cendawan mikoriza campuran (cocktail) mengingat setiap fungi mikoriza memiliki peran spesifik.

\section{DAFTAR PUSTAKA}

Ardikoesuma, R.I. dan Noerkamal. 1955. Percobaan tanaman Shorea leprosula Miq. di Jawa. Rimba Indonesia 4: 299-333.

Daryadi, L. dan Harjono. 1972. Sendi-sendi Silvikultur. Lembaga Penelitian Kehutanan, Bogor.

De la Cruz, R.E. 1982. Mycorrhizae in forestry. In : Training Course on Biological Aspect of Silviculture, BIOTROP, Bogor. Tidak dipublikasikan.Gay, J.C. dan J.C. Debaud. 1987. Genetic study on indole-3-acetic acid production by ectomycorrhizae Hebeloma species inter and intra specific variability in homo and dikaryotic mycelia. Appl. Microba Biotechnol 26 : 141-146.

Gintings, A.N., I.W.S. Dharmawan. 2007. Konservasi Tanah dan Fungsi Hidrologi Hutan Tanaman Dipterokarpa. Prosiding Seminar Pengembangan Hutan Tanaman Dipterokarpa dan Ekspose TPTII/SILIN. Balai Besar Penelitian Dipterokarpa. Samarinda.

Haeruman, H. 1975. Prosedur Analisa Rancangan Percobaan. Bagian pertama. Bagian Perentjanaan Hutan. Departemen Manajemen Hutan, Fakultas Kehutanan, IPB, Bogor. $78 \mathrm{~h}$.

Harly, J.L and S.E. Smith. 1983. Mycorrhizal Symbiosis. Academic Press, London-New York, UK-USA. Pp 483. 
Malajczuk, N.P., P. Reddell dan M. Brundrett. 1994. Role of mycorrhizae fungi in mine site reclamation. In : F.L. Pfleger and R. G. Linderman (eds). Mycorrhizae and Plant Health. 83100. pp.

Marks G.C. dan R.C. Foster. 1973. Structure, morphogenesis and ultrastructure of ectomycorrhizae. In: Marks, G.C and T.T. Kozlowski (eds). Ectomycorrhizae their ecology and physiology. Academic Press Inc. New York. 2-41.pp.

Oldeman, R.A.A., 2001. Diagnosis of Complex Ecosystems. CD Rom Dice 5.1. Easy Acess Software, Wageningen, the Netherlands.

Omon, R. M., 2002. Dipterocarpaceae: Shorea leprosula Miq., cuttings, mycorrhizae and nutrients. Tropenbos Series No 7. The Tropenbos Foundation, Wageningen, the Netherlands. 144 pp.

Omon, R.M. 2006. Pengaruh suhu dan lama penyimpanan tablet mikoriza terhadap pertumbuhan stek Shorea johorensis Foxw. di rumah kaca. Jurnal Penelitian Hutan dan Konservasi Alam Vol. III, No 1. Badan Penelitian dan Pengembangan Kehutanan, Puslitbang Hutan dan Konservasi Alam Bogor. 83-93 hal.

Priadjati, A. dan G.W. Tolkamp., 2002. Manual Persemaian Dipterocarpaceae. Badan Penelitian dan Pengembangan Kehutanan, Tropenbos International, SFMP (GTZ), APHI, IFSP (DANIDA). h. IV-1 IV-7.

Schmidt dan J. H. Ferguson, 1951. Rainfall Types based on Dry and Wet Period Ratios for Indonesia with Western New Guinea. Verhandelingen No. 42. Jawatan Meteorologi dan Geofisika, Jakarta.

Smits, W.T.M., 1994. Dipterocarpaceae: Mycorrhizae and Regeneration. Tropenbos Series No 9. The Tropenbos Foundation, Wageningen, the Netherlands.243 pp.

Soekotjo. 2007. Pengalaman dari Uji Jenis Dipterokarpa Umur 4,5 Tahun di PT Sari Bumi Kusuma Kalimantan Tengah. Prosiding Seminar Pengembangan Hutan Tanaman Dipterokarpa dan Ekspose TPTII/Silin. Balai Besar Penelitian Dipterokarpa. Samarinda.

Subiakto, A., R. Effendi dan Ernayati. 2007. Ketersediaan IPTEK pembibitan, penanaman dan pemeliharaan hutan tanaman Dipterokarpa. Prosiding Seminar Pengembangan Hutan Tanaman Dipterokarpa dan Ekspose TPTI/Silin. Balai Besar Penelitian Dipterokarpa. Samarinda.

Supriyanto, 1996. Penggunaan inokulum alganit dalam uji efektivitas pada semai beberapa jenis Dipterocarps. Laporan Penelitian 1995/1996. Direktorat Pendidikan Tinggi Proyek Pengembangan Biotrop, Bogor.35h. Tidak dipublikasikan.

Supriyanto, U.S. Irawan dan I.W.S. Dharmawan. 2003. Teknik pengemasan inokulum cendawan mikoriza. Paper dalam Seminar Tahunan Asosiasi Mikoriza Indonesia, Bandung 16 September $2003.8 \mathrm{~h}$

Yassir, I., Y. Mitikauji. 2007. Pengaruh Penyiapan Lahan terhadap Pertumbuhan Shorea leprosula Miq. dan Shorea balangeran (Korth.) Burck pada Lahan Alang-Alang di Samboja, Kalimantan Timur. Jurnal Penelitian Dipterokarpa. Vol. 1 No. 1, September 2007. Balai Besar Penelitian Dipterocarpaceae. Samarinda. 